\title{
EMERGING TECHNOLOGIES \& DISAPPEARANCE OF MANUAL LABOUR JOBS IN INDONESIA
}

\author{
Matthew Wilson SALAM and Rein SUADAMARA \\ Business Information Systems, Faculty of Computing and Media, BINUS University International, Indonesia \\ matthew.salam@binus.ac.id; rein.suadamara@binus.edu
}

\begin{abstract}
ABSTACT
With the occurrence of emerging technology, the world faces the risk of jobs being automated in the future. Labor automation itself refers to substituting technology for human labor to perform specific task or jobs. This study aims to find out whether this claim is applicable to Indonesia as a newly industrialized country and what can be done to resolve this issue? To test the hypothesis of how Labor automation can be applicable to Indonesia, this research aims to analyze the impact on how technology on jobs and what variables might be replaced in the future - using predictions from past statistics comparing how these past few years have changed with the development of technology. The research analyzed previous relevant studies on automation, how opportunities get created, how jobs get transformed, and what challenges are posed by emerging technologies. The major challenges that may be faced in this case is unemployment due to disappearing labor jobs. These results suggest that Indonesia will still be impacted with the risk of labor jobs being automated. On this basis, to prevent major unemployment issue, Indonesia needs to raise awareness for the younger generation to prepare for their future better, by enriching them with skills and ability to adapt with continuous changes.
\end{abstract}

Keywords: Technology, Labor Automation, Unemployment, Emerging Technologies

\section{BACKGROUND}

The use of technologies such as robotics process automation, cloud computing, the internet of things (IoT), machine learning, and artificial intelligence (AI) has led to significant changes in the way work is done. As newer technology continues to be introduced, more jobs have begun to shift towards being replaced. In 2015, the Foundation for Young Australian studies found that nearly $60 \%$ of young people in the country were studying or training for occupations were at least two-thirds of jobs that will be automated by the next decade. Automated jobs refer to jobs done repetitively that can be easily replaced by machines at a certain point in time. A popular example of an automated job in Indonesia is housekeeping assistant, a simple aspect such as cleaning appliances and smart devices that could assist in household chores have made a significant difference to help save up resources, in the long run, people may no longer need household assistants to clean their house and do their chores, with smart devices that are all made possible. Smart devices are everyday objects made intelligent with advanced computing, including AI and machine learning, networked to form the internet of things (IoT). A few noteworthy examples of smart devices that could be utilized currently are google home, smart LEDs, dishwashers, vacuum cleaners, etc. By having one master device to control all the other smart appliances, scheduling a house cleaning at an automated routine might be possible sooner than we thought. Another job that made a big impact if it got replaced is ojek-online, as the most working-class in Indonesia is dependent on this job. When Gojek and Grab were first introduced in Indonesia, it became a controversial issue because of the competition with taxis and other public transportations.

Eventually, they transitioned and became part of Grab and Gojek now. Although it might not be sometime soon, in 20 years, this job would be likely to get replaced with automated self-driving cars owned by big corporations. As of right now, few cars already have that feature implemented; however, it is not a luxury that everyone can afford. The objective and purpose of the study are to determine what will the impact be on society, what will happen when jobs are harder to get, by what kind of jobs would emerge and replace them. The aim of this study is to analyse whether the emergence of technology which brings out the risk of turning jobs automated also applicable in Indonesia. Hence, this paper intends to find out if these automated jobs can potentially be responsible for the disappearance of jobs in the future. Does automation put Indonesia at risk from job disappearance? If so, what attempts can be done in order to prevent mass numbers of unemployment to rise in the future? This paper looks into forecasting on how automation could take over and replace jobs in Indonesia and to find solutions that could minimize the risk of unemployment due to jobs being replaced by automation.

This research paper is built on previous related studies on emerging technology. This is even more relevant with the existing COVID-19 pandemic, Indonesia is facing an additional case of unemployment in certain parts across the country. The importance of conducting this study is to help solve this ongoing problem so that it does not escalate into a more significant issue; having a job during this pandemic is necessary, yet some people are unable to work due to various reasons. Labor automation is the practice of substituting technology for human labour to perform specific tasks or jobs. The theory on job loss by McKinsey and Company (2017) estimated that $49 \%$ of activities that people do, as part of their jobs, have the potential to be automated., in which about $30 \%$ of activities of $60 \%$ of jobs could technically be automated. In comparison, less than $5 \%$ of jobs consisted of activities that can be completely automated. Around 85 million jobs can be displaced by 2025 as a new generation of smart machines takes over a larger portion of job roles and $43 \%$ of businesses reveal that they are set to cut down on their workforce due to the integration of new technology (World Economic Forum, 
2020). In Central and Eastern Europe (CEE), 36\% of the jobs threatened by the COVID-19 pandemic are also at risk of being displaced because of automation adoption by 2030 (McKinsey \& Company, 2020). E-commerce is the buying and selling of good or services via the internet, and the transfer of money and data to complete the sales. Another issue to consider is the majority of the traditional generation in the working class are struggling due to the limitation from the general public that follows the work from home routine, whereas the livelihood of traditional merchants, shopkeepers, and small food stalls owners are entirely dependent on the number of sales they can make each day. Compared with the performance of millennials who can better utilize the IoT (internet of things) such as using online shop, the use of instant couriers and social media to expand the exposure of their brand further, more people will then be aware of their business. Advanced robotics are a combination of sophisticated programming and powerful hardware that make use of smart sensor technology (including ultrasonic, touch, and light sensors) to interact with the real world around it. The application of advanced robotics in automated jobs are usually involved with production method, for example on instant food factories. Artificial intelligence (AI) refers to the simulation of human intelligence in machines that are programmed to think like humans and mimic their actions. The application of AI can be seen on autonomous cars, wheeled vehicles that are able to operate without a human driver.

\section{METHOD}

\section{Data collection}

These are the projection gathered by the US labor regarding the statistics of jobs being lost due to automation; however, this data is based on the United States. This study aims to predict the statistics from Indonesia. As there is not sufficient data regarding this issue from Indonesian studies, this research used the data on unemployment derived from Lokadata. The research method used in obtaining the corresponding data are gathered using a series of available resources and statistics gathered from previous studies and statistics revolving around employment. The initial study was taken from the US Bureau of Labor Statistics. It measures the statistics based on the educational attainment for each individual as part of the total population. Another collection of data is also gathered from Lokadata (from Indonesia) to compare and analyze the results. These data can later be combined and evaluated using the forecasting method to find the correlation of education with unemployment. Afterwards, using that projected data, it will then be compared with other statistics that predict which job will be lost in the future using prediction from the data given below.

\section{Data Analysis}

The data provided by Lokadata (figure 1) range from all places across Indonesia; it pinpoints the highest unemployment rate, and from those statistics are further categorised into the demographic and education category. From the data given by Lokadata, it is visible that in Indonesia, the majority of unemployment comes from those with the educational attainment of SMK, SMA and S1/diploma, ranging from highest to lowest. When comparing with the data shown by the Bureau of Labor Statistics (figure 2), the peak of unemployment in the United States always belong to those who didn't finish high school category (the lowest) and hasn't change throughout the years. The difference between the two data lies in the placement of the chart; from the Bureau of Labor, it is clear that higher education yields a lower number on the unemployment rate. However, this is not applicable to the data provided by Lokadata. So in order to get a more accurate result, another set of data is taken from Badan Pusat Statistik (figure 3) also shows consistent result, it shows that SMK graduates contributes the highest unemployment rate in Indonesia. The reason why SD \& SMP (elementary \& middle school) graduates have lower unemployment rate compared to SMK is because the numbers of elementary graduates has decrease, while the numbers on SMP \& SMK graduates continue to increase, the determining factor in this case is based on the increased number of competitions, which follows the law of supply and demand, where there is too much supply (workforce), but only a few demands (the job). To make the comparison, easier The Bureau of Labor Statistics displays four categories to divide the education level, which is below high school diploma, high school graduate, college degree, and bachelor degree or higher is the highest. When being compared with the Indonesian category by Lokadata, below high school diploma is the same as SMP \& SD, high school graduate equals to SMA, college is equalled to $\mathrm{SMK}$, and bachelor degree or higher equals to S1 up to S3 in Indonesia. Using the variables from the Lokadata statistics, the data only shows the unemployment rate and not the reason; thus, it cannot be evaluated further to determine the cause of the unemployment itself. To specify the data, more information is needed on statistics regarding jobs being lost to automation as it is the main topic of this research.

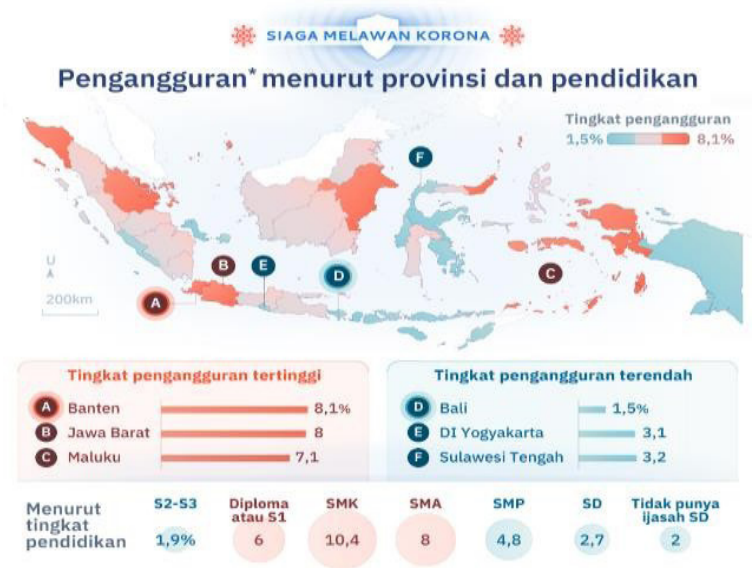

Figure 1. Lokadata Statistics on unemployment 


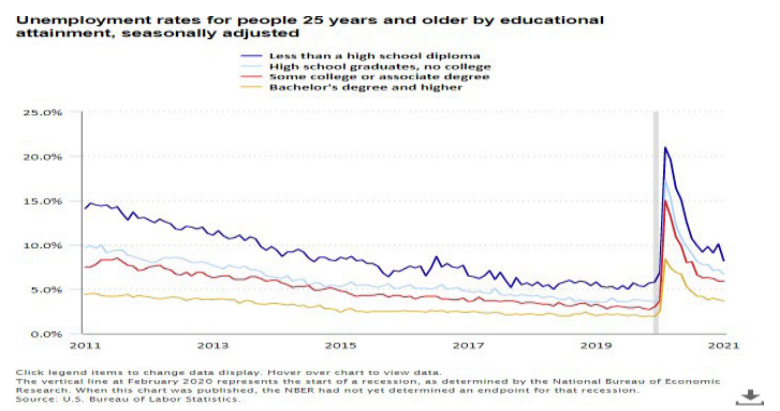

Figure 3. BPS Statistics on unemployment

Tingkat Pengangguran Terbuka Menurut Jenjang Pendidikan (Februari 2019-2020)

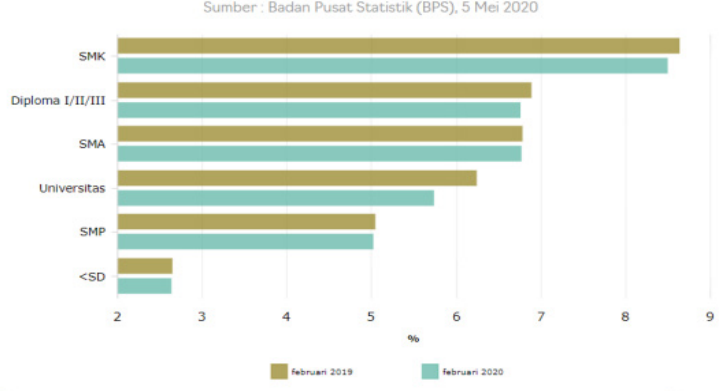

Dkatadata

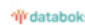

Figure 2. Bureau of Labor Statistics data on unemployment

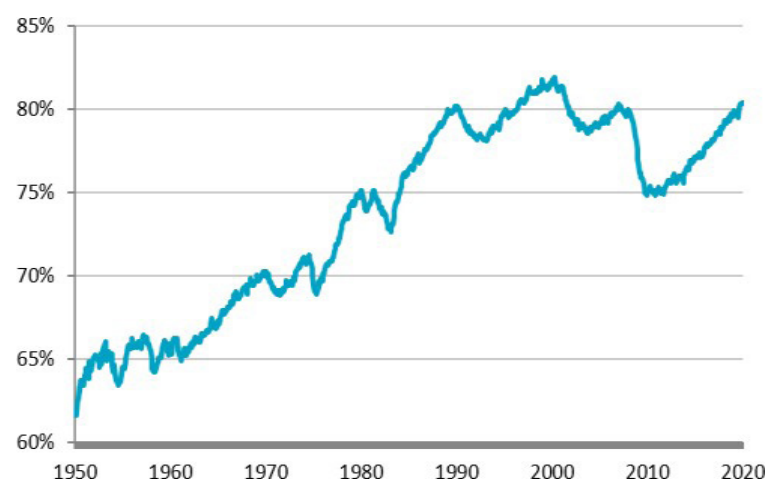

Figure 4. Bureau of Labor Statistics on Automation

The graph in figure 4 shows the number of jobs being replaced with automation by the US Bureau of Labor Statistics (source: econsultsolutions.com). To forecast the rate of jobs that can potentially be replaced by automation in Indonesia, an exact percentage of jobs lost to automation is needed to create a forecast projection for the next 30 years in Indonesia. The forecast is done in 2 trials, first in the range of 5 years, and another with the range of every year. The percentage is then gathered by using grids to pinpoint the exact point of each year. The range is recorded in the multiple of 5 years and 1 year to minimise further the margin of error. Refer to the picture in figure 5, the red dots indicate the points in which year did the percentage value yields. This is the graph that will be used on the first trial. For the second trial a more indepth grid is needed to determine a much more detailed result. Here is the sample of the graph that will be used for the second trial, as shown in the figure 6 . The red dots indicate the points in which the percentage are in every year. After inputing the data, everything will be used in a formula using the forecast on the spreadsheet to determine the prediction value for the upcoming forecast of 2021 to 2050 .

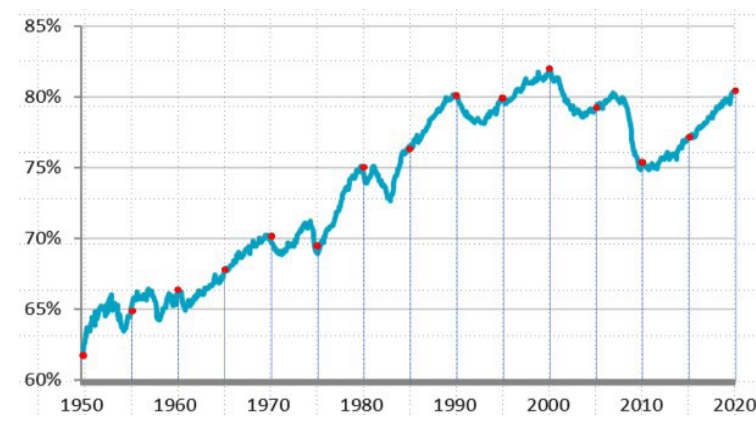

Figure 5. Bureau of Labor Statistics on Automation First Trial

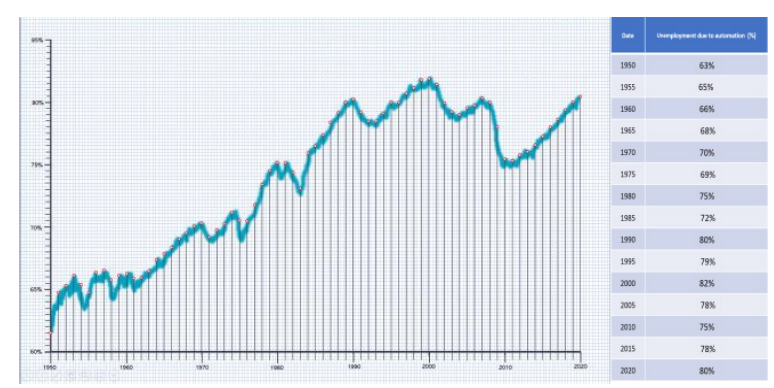

Figure 6. Figure 6. Bureau of Labour Statistics on Automation Second Trial

\section{RESEARCH AND DISCUSSION}

Now that all the data are present, it is now possible to create a forecast projection for the rate of jobs replaced by automation. According to the prediction, the rate of jobs being replaced by automation increases in a linear formation. It is shown as linear because it indicates the median point for each year's rate. The prediction is made using the formula of FORECAST.EST by using the rate of its growth from 1950 to 2020 as its base value. The forecast range is made for 30 years ranging from 2021 to 2050 , and here is the result of the first trial projection.

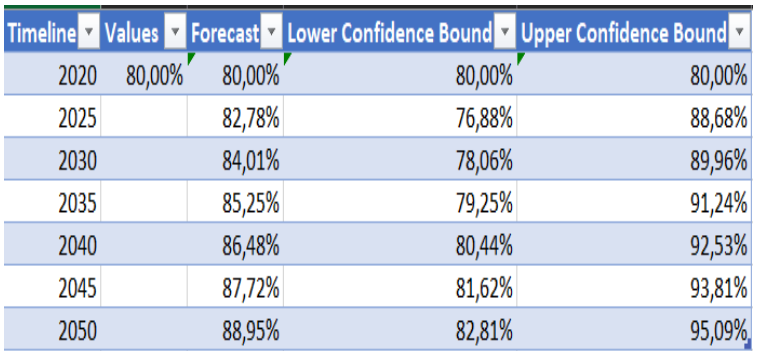

Table 1. Forecast on Automated Jobs (Trial 1)

Refer to the Table 1 above, to get the value for each year, the syntax needed for FORECAST.ETS is written in these exact order (target date, values, timeline, [seasonality], [data_completion], [aggregation]). The data inputted are target date, values and timeline (from the previous 1950 - 2020 chart), the seasonality and data completion are set to 1 , and for the aggregation is set as default which is for average. In these forecast the confidence level is set at $95 \%$, this way a prediction can be made showing lower and upper confidence with the accuracy of $95 \%$ based on the provided data. In this forecast the results is shown in 3 categories, which are the upper confidence, lower confidence, and average. The upper confidence shows the highest point that the 
forecast can predict, the lower confidence shows the lowest point that the forecast can predict, meanwhile the average shows the median point between the result of the two confidences, refer to figure 8 for the values of the first trial.

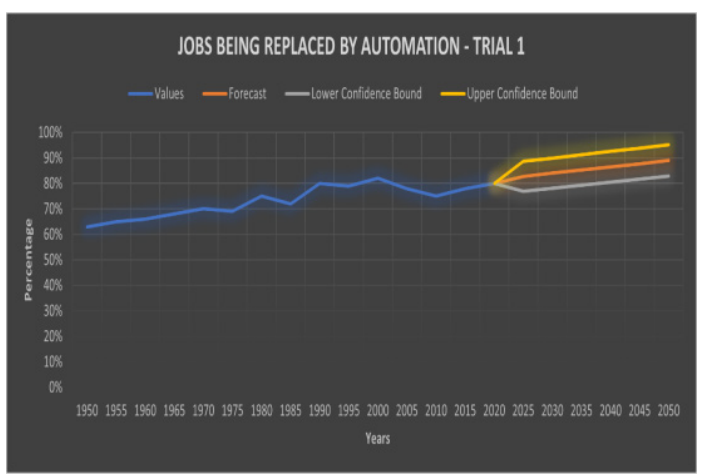

Figure 8. Forecast Values of Trial 1

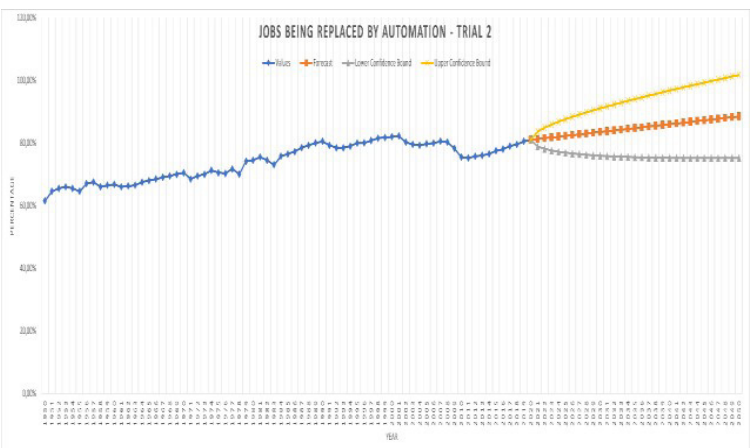

Figure 9. Forecast on Automated Jobs (Trial 2)

The result of the second trial is shown in figure 9, from these two trials, the analysis provided by the second trial yields higher value compared with the first trial, refer to Table 2. The result from the second trial shows a wider range and is more accurate compared to the first trial, as the data taken for the sample in the second trial is taken every year, this way the rate of increase and decrease from each year is recorded and put into consideration for the forecast. Other than reviewing the forecast, here is several other research regarding jobs that would disappear due to automation in general; refer to the picture in Figure 11, which is taken from a study by Mckinsey Global Institute.

\section{Table 2. Forecast Values of Trial 2}

\begin{tabular}{|c|c|c|c|c|}
\hline 2020 & $81,00 \%$ & $81,00 \%$ & $81,00 \%$ & $81,00 \%$ \\
\hline 2021 & & $81,25 \%$ & $78,87 \%$ & $83,63 \%$ \\
\hline 2022 & & $81,50 \%$ & $78,13 \%$ & $84,87 \%$ \\
\hline 2023 & & $81,75 \%$ & $77,62 \%$ & $85,87 \%$ \\
\hline 2024 & & $82,00 \%$ & $77,23 \%$ & $86,76 \%$ \\
\hline 2025 & & $82,25 \%$ & $76,91 \%$ & $87,58 \%$ \\
\hline 2026 & & $82,49 \%$ & $76,65 \%$ & $88,34 \%$ \\
\hline 2027 & & $82,74 \%$ & $76,43 \%$ & $89,06 \%$ \\
\hline 2028 & & $82,99 \%$ & $76,24 \%$ & $89,75 \%$ \\
\hline 2029 & & $83,24 \%$ & $76,08 \%$ & $90,41 \%$ \\
\hline 2030 & & $83,49 \%$ & $75,93 \%$ & $91,05 \%$ \\
\hline 2031 & & $83,74 \%$ & $75,81 \%$ & $91,67 \%$ \\
\hline 2032 & & $83,99 \%$ & $75,70 \%$ & $92,28 \%$ \\
\hline 2033 & & $84,24 \%$ & $75,61 \%$ & $92,87 \%$ \\
\hline 2034 & & $84,49 \%$ & $75,53 \%$ & $93,45 \%$ \\
\hline 2035 & & $84,74 \%$ & $75,46 \%$ & $94,02 \%$ \\
\hline 2036 & & $84,99 \%$ & $75,40 \%$ & $94,57 \%$ \\
\hline 2037 & & $85,24 \%$ & $75,35 \%$ & $95,12 \%$ \\
\hline 2038 & & $85,48 \%$ & $75,31 \%$ & $95,66 \%$ \\
\hline 2039 & & $85,73 \%$ & $75,27 \%$ & $96,20 \%$ \\
\hline 2040 & & $85,98 \%$ & $75,24 \%$ & $96,72 \%$ \\
\hline 2041 & & $86,23 \%$ & $75,22 \%$ & $97,24 \%$ \\
\hline 2042 & & $86,48 \%$ & $75,21 \%$ & $97,76 \%$ \\
\hline 2043 & & $86,73 \%$ & $75,20 \%$ & $98,27 \%$ \\
\hline 2044 & & $86,98 \%$ & $75,19 \%$ & $98,77 \%$ \\
\hline 2045 & & $87,23 \%$ & $75,19 \%$ & $99,27 \%$ \\
\hline 2046 & & $87,48 \%$ & $75,20 \%$ & $99,76 \%$ \\
\hline 2047 & & $87,73 \%$ & $75,20 \%$ & $100,25 \%$ \\
\hline 2048 & & $87,98 \%$ & $75,22 \%$ & $100,73 \%$ \\
\hline 2049 & & $88,23 \%$ & $75,23 \%$ & $101,22 \%$ \\
\hline 2050 & & $88,47 \%$ & $75,26 \%$ & $101,69 \%$ \\
\hline
\end{tabular}

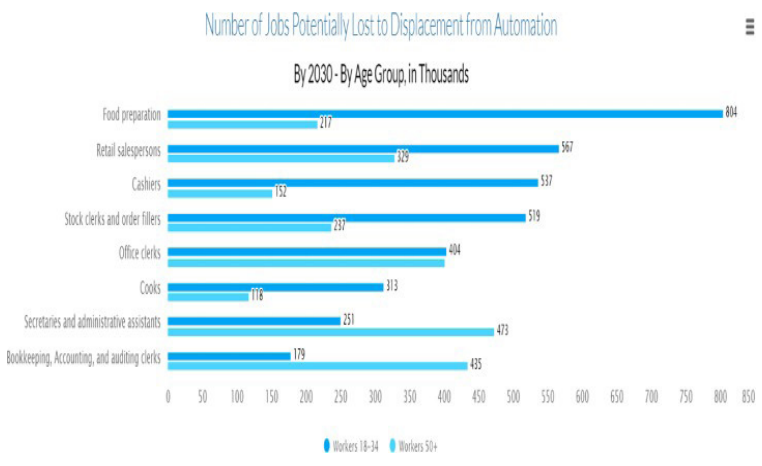

Figure 11. Jobs that will be replaced according to McKinsey Global Institute

From these data, it is visible that the highest number would be on food preparation, which means the competition for being restaurant staff in Indonesia would be harder to get by. Based on these data, the category is divided by age, separating the younger generation of workers from the older ones. This is done because the jobs with a younger workforce require more activity that usually requires moving more; meanwhile, the ones with more older generation present tends to have more deskwork and usually involves being in an office. Although these jobs would be put out of place due to automation, there is an alternative method to prevent more unemployment by redirecting the younger generation to pick up jobs or study plan that has a lower risk of getting replaced by automation. This can be done by starting to raise awareness at an early age by analysing the opportunities and risks that impact job automation and the competition globally. Another method is to ensure that more people in Indonesia can receive higher education; this can be done by investing more funds in education, giving more scholarships and even expanding government-owned schools to more rural areas in the vicinity.

\section{CONCLUSION}

In conclusion, the objective of this research to answer the previous research question of "Does automation put Indonesia at risk from job disappearance?" the answer is yes, this can be proven from the results gathered, the rate of jobs that will be replaced by automation will continue to increase as shown by the results in the 2 trials, both trials shows that the rate will continue to increase as of 2050. Based on the analysis above the forecast shows that in the upcoming 30 years an estimated minimum of $75 \%$ on jobs will be replaced by automation, according to the forecast result from the second trial. As for the second objective on "what attempts can be done in order to prevent mass numbers of unemployment to rise in the future? The answer has not been achieved yet in this paper, due to the limitation and the current government policy of PPKM in Indonesia, and thus a throughout research of collecting data from professionals on this sector has not been gathered yet. Future studies can be attempted to gain this information by consulting with professionals who are experts on the sector of job employment and automation. 


\section{REFERENCES}

A Jain, S Ranjan. (2020). Implications of emerging technologies on the future of work. IIMB Management Review, 2020 - Elsevie

E Parry, V Battista. (2019, January). The impact of emerging technologies on work: a review of the evidence and implications for the human resource function. Emerald Open Res, volume 1 , issue 5

Foundation for Young Australians (2015), The new work order: ensuring young Australians have skills and experience for the jobs of the future, not the past, Foundation for Young Australians

Kande, M., \& Sönmez, M. (2020, October 26). Don't fear AI. The tech will lead to long-term job growth. World Economic Forum. Retrieved April 22, 2021
McKinsey \& Company. (2020). Digital challenges in the next normal: Central and Eastern Europe on a path to digitally-led growth. McKinsey \& Company.Peruffo, E., Schmidlechner, L., \& Contreras, R. R. (2017). Automation of work: literature review. Dublin: Eurofound.

Prakasa, K. (2021, January 7). Pertarungan pengangguran karena Korona. Lokadata.ID.

Pricewaterhouse Coopers. (2020). PwC's global artificial intelligence study: Sizing the prize. PwC.

PricewaterhouseCoopers. (2021). PwC 24th annual global CEO survey: A leadership agenda to take on tomorrow. PwC. https://www.pwc.com/gx/ en/ceo-agenda/ceosurvey/2021/report.html

PwC UK. (2018, February). Will robots really steal our jobs? An international analysis of the potential long- term impact of automation. $\mathrm{PwC} \mathrm{UK}$. 